(2) Open Access Full Text Article

REVIEW

\title{
Anterior Cruciate Ligament Injuries in Australian Rules Football: Incidence, Prevention and Return to Play Outcomes
}

This article was published in the following Dove Press journal: Open Access Journal of Sports Medicine

\author{
Kate E Webster (D) $^{\prime}$ \\ Timothy E Hewett ${ }^{2}$ \\ Julian A Feller ${ }^{1,3}$ \\ 'School of Allied Health, Human Services \\ and Sport, La Trobe University, \\ Melbourne, VIC, Australia; ${ }^{2}$ Hewett \\ Global Consulting, Rochester MN \& \\ Rocky Mountain Consortium for Sports \\ Research, Edwards, CO, USA; \\ ${ }^{3}$ OrthoSport Victoria, Epworth \\ HealthCare, Melbourne, VIC, Australia
}

Correspondence: Kate E Webster

School of Allied Health, Human Services and Sport, College of Science, Health and Engineering, La Trobe University, Melbourne, Victoria, 3086, Australia,

Email k.webster@latrobe.edu.au

\begin{abstract}
Australian Rules football is the most popular of the various codes of football played in Australia. During the game players perform frequent landing, cutting and pivoting manoeuvres that expose them to substantial risk for anterior cruciate ligament (ACL) injury. Recent years have seen the introduction of a professional women's league that has resulted in an exponential growth in the participation of women and girls in this sport. Unfortunately, there is a corresponding growth in ACL injury rates in female players. This review summarizes the incidence of ACL injury in both men's and women's Australian Rules football and reviews potential causative factors and risk reduction strategies. The final section takes an in depth look at return to sport outcomes after ACL reconstruction surgery in these populations. Whilst an ACL injury does not mean the end of a player's career in Australian football, it certainly presents a significant challenge in terms of return to preinjury levels of form and high rates of secondary and tertiary ACL injury are also a significant concern.
\end{abstract}

Keywords: Australian football, knee injury, ACL, injury prevalence, return to play

\section{Introduction}

Australian Rules football is a field-based, athletically demanding team sport that attracts a broad spectrum of participants; from children and adult communities to the national professional competitions that are known as the Australian Football League (AFL) and the Australian Football League Women's (AFLW). Australian Rules football is the most popular of the various codes of football played in Australia (including Australian Rules, soccer, rugby union and rugby league) and the number of participants is estimated to exceed 1.7 million. ${ }^{1}$ Since the start of the AFLW in 2017, female participation in football has seen a rapid growth in the number of women's clubs in Australia, with clubs having increased 137\% (from 960 to 2281 clubs), in just two seasons. ${ }^{2}$

Australian Rules is played on natural grass with an oval leather ball, usually during the winter months. Two teams contest play over 4 periods of 20 minutes in the men's competition and 15 minutes in the women's competition, plus time on field for stoppages, with the objective to score more points than the opposition team to win. Teams consist of a total of 22 players with 18 allowed on the field at any one time in the men's competition and 16 in the women's competition. The typical playing field is larger than other codes of football (approx. $165 \times 135 \mathrm{~m}$ ) and most of these fields are also used for cricket in the summer months. Various game 
modifications are made at the junior level. A thorough description of player positions and scoring can be found in Gray and Jenkins ${ }^{3}$ and further game details including videos of match play can be found on the AFL website (www.afl.com.au).

Previous studies have documented the physiological and technical demands of match play in both the men's and women's competitions. ${ }^{4-6}$ Global positioning system (GPS) technology was first permitted in 2005 and when all playing positions are pooled the average distances covered by players during a game is approximately $12 \mathrm{~km}$ for men and $6 \mathrm{~km}$ for women with top speeds of $35-36 \mathrm{~km} / \mathrm{hr}$ also recorded. ${ }^{3,7}$ The game is both aerobic and anaerobic with players required to make and avoid contact with the opposition by disposing of the ball by hand or foot. The ball may be disposed of in any direction and consequently a player may be tackled from any direction. Therefore, players perform many landing, cutting and pivoting manoeuvres per game, which exposes them to substantial risk for anterior cruciate ligament (ACL) injury which is at least comparable to that of other popular team balls sports including American football, soccer and rugby. $^{8-11}$ The purpose of this review is to summarize the incidence of ACL injury in both men's and women's Australian football, discuss the injury mechanism and risk reduction strategies and evaluate return to sport outcomes after ACL reconstruction surgery.

\section{Incidence and Prevalence of ACL Injuries in Australian Football}

Since 1996 the AFL has publicly released an annual injury report, in which injury is defined as any physical or medical condition that causes a player to be unavailable for a match in the regular season or finals. Injury prevalence is defined as the number of missed games per club per season. Further details regarding injury surveillance in Australian football can be found in Orchard et $\mathrm{al}^{12}$ and Saw et al. ${ }^{13}$

The club incidence of ACL injuries in the AFL has been consistent over the past decade with just under one (0.8) injury per club per season. ACL injuries are the second most prevalent injury in the AFL (after hamstring injuries) and in 2019 ACL injuries caused 17.9 missed games per club per season and are therefore a significant burden both in treatment costs and missed matches (Table 1). ${ }^{14}$ ACL injuries tend to occur early during the playing season and preseason training. ${ }^{15}$ A tenyear surveillance study reported that $5 \%$ of players sustained an ACL injury. ${ }^{16}$
Table I Incidence and Prevalence of ACL Injuries Between 2017 and 2019 in the AFL and AFLW

\begin{tabular}{|l|c|c|c|}
\hline Measure & $\mathbf{2 0 1 7}$ & $\mathbf{2 0 1 8}$ & $\mathbf{2 0 1 9}$ \\
\hline AFL & & & \\
Incidence & 0.56 & 0.9 & 0.87 \\
Incidence per 1000 player hours & 0.7 & 1.1 & 0.7 \\
Prevalence & 14.22 & 15.96 & 17.90 \\
\hline AFLW & & & \\
Incidence & 1.0 & 1.13 & 0.9 \\
Incidence per 1000 player hours & 4.31 & 6.47 & 5.14 \\
Prevalence & 5.38 & 6.88 & 4.80 \\
\hline
\end{tabular}

Notes: Incidence refers to the number of $\mathrm{ACL}$ injuries per club per season; prevalence refers to the number of missed games per club per season.

In the first three years of the AFLW, on average, one ACL injury was sustained per club per season. Half to two-thirds of these ACL injuries occurred during match play. Whilst, in 2019, ACL injuries in the AFLW resulted in 4.8 missed matches per club (Table 1), the AFLW season is considerably shorter than the AFL season and when exposure is considered ACL injuries were the most frequent injury to occur per 1000 player hours. ACL injuries also occurred at a highly concerning six (6) times higher rate in the women's compared to men's competitions (Figure 1), which already have among the highest rate across sports worldwide.

Comparison with other sports that have reported sex discrepancies in ACL injury incidence further highlights the high incidence rate of ACL injuries in the AFLW. For example, in elite women's soccer the mean incidence of ACL injury during match play is reported at approximately 0.72 injuries per 1000 player hours and twice that of the men's competition (Swedish Men's and Women's First Leagues). ${ }^{17}$ Even in team handball, which is thought to have among the highest ACL injury rates, incidence rates for women are much lower than in the AFLW. For example, a mean incidence of 1.6 ACL injuries per 1000 hours of play has been reported for women playing in Division 1 of the European competition which is three times greater than the men's elite team competition. ${ }^{18}$ Therefore, when AFLW is compared to these other team sports, the ACL injury rate is 3-7 times higher when compared to female players and 10-19 times higher when compared to male players (Table 2). It must be noted that these are illustrative examples and do not represent all epidemiological data for the sports of handball and soccer. 


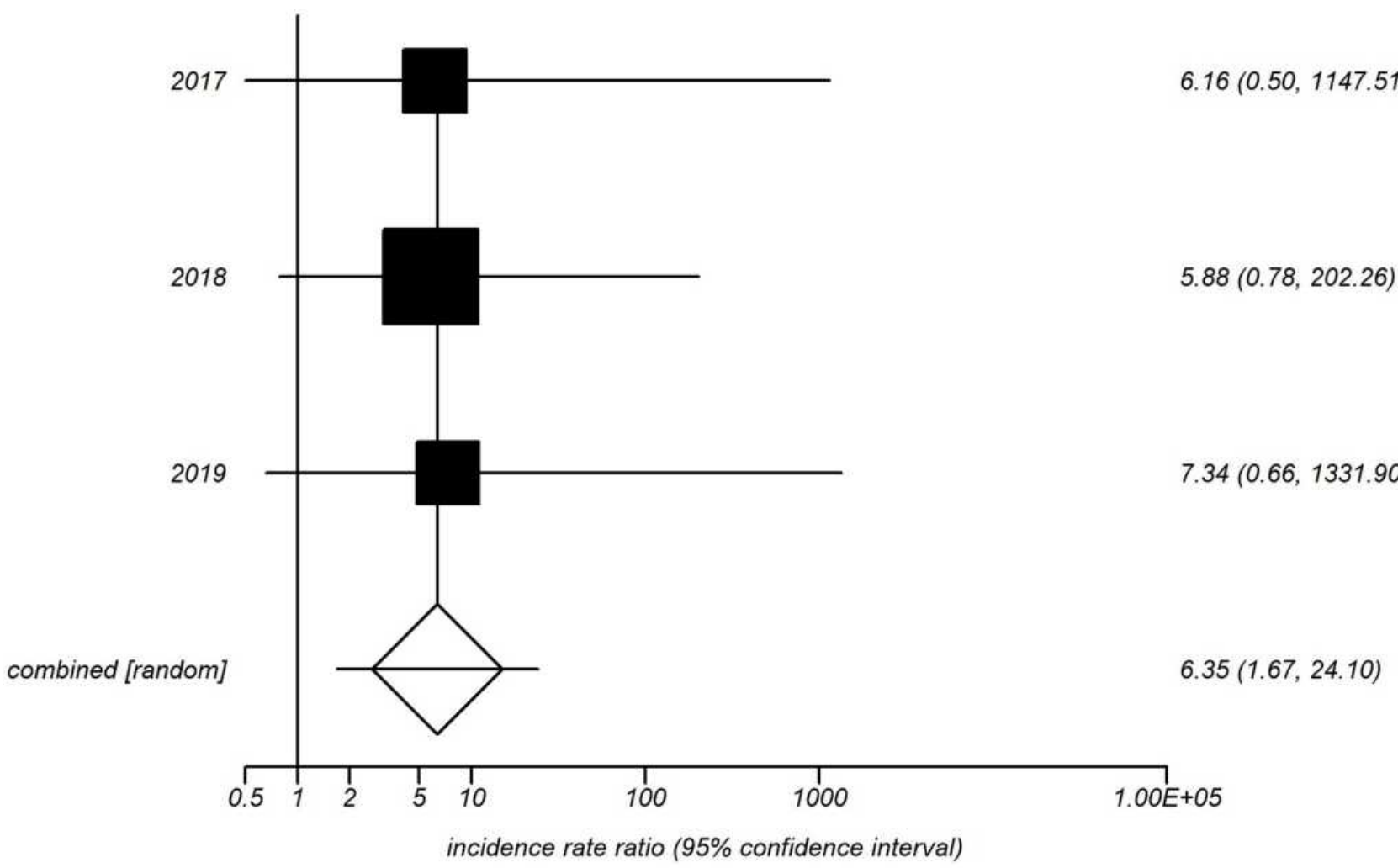

Figure I Combined incidence rate ratio of ACL injuries for 2017-2019 seasons comparing AFL and AFLW. Positive values indicate a higher incidence in AFLW compared to AFL. The incidence rate was on average 6.35 times higher in the AFLW compared to the AFL during this time frame.

At the non-elite level, Australian football has the second highest incidence of ACL injury per participant after skiing. ${ }^{19}$ The annual ACL reconstruction incidence per 100,000 person-years was estimated to be 273 for nonelite level Australian football. ${ }^{19}$ This is significantly lower than the estimation of 1945 ACL reconstructions per 100,000 player-years for the professional level AFL. ${ }^{19}$ This disparity between elite and non-elite levels is perhaps not surprising and may in part relate to the challenges of community-level injury surveillance as there is no universal tracking system in Australia. Many, if not most people with ACL injuries do not initially attend a hospital and any estimate of ACL injury rates is therefore likely to be low.
It is also relevant to note that none of the available community injury surveillance data will reflect the recent considerable increase in women's participation in Australian football.

\section{Risk Factors for ACL Injury and Risk Reduction Strategies Men's Australian Football}

The causative factors that contribute to ACL injury in Australian football are a topic of ongoing debate. In the AFL there has been much discussion regarding extrinsic factors such as the playing surface, ground hardness and

Table 2 Relative Increase in Risk for ACL Injury in the AFLW and AFL Compared to Example Studies in Elite Level Soccer and Handball

\begin{tabular}{|l|c|c|c|c|}
\hline & \multicolumn{2}{|c|}{ Soccer ${ }^{17}$} & \multicolumn{2}{c|}{ Handball $^{18}$} \\
\cline { 2 - 5 } & Men's Competition & Women's Competition & Men's Competition & Women's Competition \\
\hline Incidence per 1000 player hours & 0.28 & 0.72 & 0.54 & 1.62 \\
Relative increase in risk for AFLW & 18.9 & 7.4 & 9.8 & 3.3 \\
Relative increase in risk for AFL & 2.9 & 1.1 & 1.5 & 0.5 \\
\hline
\end{tabular}

Notes: ${ }^{\mathrm{a}} \mathrm{AFLW}$ Incidence $=5.3 \mathrm{ACL}$ injuries per 1000 player hours average for $2017-2019$ seasons. ${ }^{\mathrm{b}} \mathrm{AFL}$ Incidence $=0.8 \mathrm{ACL}$ injuries per 1000 player hours average for 2017-2019 seasons. 
boot type. Research around these topics has shown that there is a greater incidence of ACL injury in warmer regions, which was hypothesised to be due to higher traction forces when playing on warm season grasses. ${ }^{20-22}$ Similar regional differences have also been reported for European soccer. ${ }^{23}$ Trends towards increased risk of ACL injury with harder ground surfaces have been shown at the elite level. ${ }^{20}$ At the community level injury risk of all injuries combined has also been shown to be associated with ground hardness. ${ }^{15,24}$ Rule changes also influence the style of play, which may serve to increase or decrease injury risk and these have been reviewed elsewhere. ${ }^{3}$

Biomechanical characteristics of the manoeuvres that cause ACL injury during play have also been studied to inform the development of training programs to reduce the risk of ACL injury. ${ }^{25}$ In the AFL, video analysis of ACL injuries during match play has shown that the majority of ACL injuries occur in non-contact situations when the knee is close to extension while sidestepping or landing from a manoeuvre. ${ }^{26}$ Approximately half occur during decelerations at a slow to medium jogging speed. It has therefore been advised that training programs should target muscle activation strategies that stabilise valgus and internal rotation movements of the knee and tibia relative to the femur during sidestepping and landing. ${ }^{26}$

Overall, elite-level teams have a good understanding of ACL risk factors and risk reduction programs have been implemented. ${ }^{27}$ However, they continue to experience a relatively high number of ACL injuries and as previously noted, the incidence of ACL injures has not decreased over the past decade. This does not indicate that the incorporation of selected training drills to reduce the risk of ACL injuries have no benefit but may rather highlight the inherently high risk for ACL injury in elite-level Australian football. Results of training programs designed to reduce injury risk have shown promising results at a community level. A large randomized controlled trial demonstrated that a targeted neuromuscular exercise training program that was incorporated into regular training sessions could reduce the risk of all lower limb injuries by $22 \%$ and knee injuries by up to $50 \%$ in male football players. ${ }^{28}$

\section{Women's Australian Football}

The ACL injury mechanism for female players has also been documented with video analysis across three AFLW seasons. ${ }^{29}$ Overall, ACL injuries were evenly distributed between sidestep manoeuvres, linear decelerations and single-leg landings and most often included situations when the ball was in contest. Such contests often included indirect contact and in just over half of the ACL injuries, the trunk was in a forward or laterally flexed position. ${ }^{29}$ Such altered trunk motion and control shifts the centre of mass outside of the base of support, thus increasing the mechanical demand on the supporting structures down the kinetic chain. ${ }^{30}$

In terms of risk factors that may contribute to the high ACL injury incidence in females, the large majority $(80 \%)$ of ACL injuries in the AFLW have occurred during preseason training or in the first half of the season. ${ }^{29}$ This has led to suggestions that AFLW athletes have been inadequately prepared for game demands, but the same observation of high rates of injury in the first half of the season has also been made in men's football. ${ }^{15}$ It has also been noted that women are less likely to have played Australian football from an early age. In addition, the women's seasons and accompanying preseasons are short relative to the men's, so women have less time to adapt to the biomechanical and neuromuscular requirements of the sport. However, these factors are currently speculative and further work is required to fully evaluate their validity and to explore other potential causative factors.

Concept mapping methodology has recently been used to enhance the knowledge of ACL risk reduction programs in women's Australian football. ${ }^{31}$ It was determined that, in order of importance; movement skills, football-specific preparation, education, strength and conditioning and individual preparation should be included in injury risk reduction programs for women participating in elite-level Australian football. As adherence to such programs has been highlighted as problematic in other contexts, the engagement of those who are responsible for the implementation of such programs, as well as end end-users, was adopted to better address such issues. Whilst such elements would likely provide a solid foundation for the development of programs that may ultimately reduce injury risk in elite female Australian footballers, empirical evidence of their validity is still to be achieved. Nonetheless, it is well demonstrated that participation in multi-component exercise-based programs can reduce ACL injury risk by half for all ACL injuries and by twothirds for non-contact (ie likely caused by neuromuscular control deficits and therefore more preventable) ACL injuries in female athletes from a variety of high-risk sports, including at the elite level. ${ }^{32}$ Even so, ACL injury risk reduction by 50 to $67 \%$ in the AFLW would still result in 
an injury rate in the range of 2 to 3 times greater than the AFL.

\section{Return to Sport Outcomes After ACL Reconstruction}

In elite sport, most athletes who sustain an ACL injury elect to undergo ACL reconstruction surgery to optimize their chance of returning to play. In Australian football, a 15-year registry of AFL players with ACL injury did not identify any complete ACL ruptures that were managed non-operatively. ${ }^{33}$ Therefore, this section on return to sport outcomes will focus on players who have had ACL reconstruction surgery. Return to sport rates, return to sport performance and further injury will specifically be the focus of discussion. Due to the relative infancy of participation by women and girls in Australian football, and thus a lack of data on return to sport outcomes in female athletes, this section primarily documents outcomes in male elite and non-elite level players.

\section{Rates and Timing of Return to Play}

Three audits have been conducted on ACL injuries in the AFL from prospective records made available by the AFL Medical Officers Association. ${ }^{16,33,34}$ The first by Liptak et $\mathrm{al}^{16}$ which only included players who had sustained a first time ACL injury covers the time period 1990-2000; the second by Lai et al $^{33}$ covers 1999-2013; the third by Chaker Jomaa et $\mathrm{al}^{34}$ covers 1992-2014, and collectively span 25 years of play. The audit by Liptak et al reported that $4.8 \%$ of AFL players sustained an ACL injury. With regard to return to play, data from these audits are consistent and show that between $74-77 \%$ of AFL footballers who had ACL reconstruction surgery were able to return to elite level play (Table 3). Lai et $\mathrm{al}^{33}$ separately documented return to play rates for players who had sustained multiple ACL injuries and reported a slightly lower rate of $71 \%$ (34 out of 48 players) after a second ACL injury and 64\% (9 out of
14 players) after a third. This is consistent with findings from the NFL in which return to sport rates remain high for players with multiple ACL injuries. ${ }^{35}$

There is often significant pressure for an elite-level athlete to make a timely return to play and in the AFL players have returned as early as 4 months post-surgery. ${ }^{33}$ However, most players do not return until around the 12month mark, which equates to approximately 21.5 AFL home and away matches. ${ }^{16,33}$ Players who return from a second ACL injury take slightly longer and return on average at 14 months post-surgery or 23 AFL home and away matches. ${ }^{33}$ However, players who received an artificial ligament graft (Ligament Augmentation and Reconstruction System; LARS graft) returned to play significantly sooner than after an autograft reconstruction - at a mean 7.6 months and missing 10.6 fewer matches. ${ }^{33}$ However, outcomes for LARS grafts have been reported to vary greatly and will be discussed further below.

At the non-elite level, there are limited data that are specific to Australian football. Ardern et $\mathrm{al}^{36}$ reported return to sport rates at 12 months following ACL reconstruction in a cross-sectional study of 503 patients in which the majority participated in Australian football. Rates for return to full competition at this post-surgical timepoint were greatest for those who played Australian football (42\% return rate) followed by basketball $(39 \%)$, soccer $(29 \%)$ then netball $(19 \%)$. Based on these limited data, return rates are higher in Australian football than other sports and fewer non-elite level athletes return to play over the first year after ACL reconstruction compared to elite athletes. This is probably not surprising but there is a paucity of data on return rates after ACL reconstruction in non-elite Australian footballers beyond the first postsurgical year to determine how many players eventually make a return. Thus, there remains a need for further data on return to Australian football after ACL reconstruction for the non-elite level athlete.

Table 3 Return to Play Rates and Factors Associated with Return to Play from ACL Injury Audit Studies in the AFL

\begin{tabular}{|l|c|c|c|c|}
\hline Study & Time Period & Number of Players & Return to Play Rate & Factors Associated with Return to Play \\
\hline Liptak et al ${ }^{16}$ & $1990-2000$ & 115 & $74 \%(85 / 115)$ & $\begin{array}{c}\text { Side of injury } \\
\text { Age } \\
\text { Weight }\end{array}$ \\
\hline Lai et al & & & $77 \%(121 / 158)$ & $\begin{array}{c}\text { Playing experience } \\
\text { Draft pick }\end{array}$ \\
\hline Chalker Jomaa et al ${ }^{34}$ & $1994-2014$ & 324 & $77 \%(248 / 324)$ & Not analysed \\
\hline
\end{tabular}




\section{Factors Associated with a Return to Play}

Numerous factors have been explored for their potential association with return to play in the AFL following ACL injury and those that have shown significant associations are listed in Table 3. Players who injured their dominant side were found to be 9 times less likely to play again compared to players who injured their non-dominant side in the initial AFL audit by Liptak et al. ${ }^{16}$ Associations between demographic characteristics and return to play exist. Age plays a role, as players aged 30 years or older are less likely to return compared with younger players (aged between 17-20 years). ${ }^{16}$ Body mass also plays a role, as moderate weight players $(90-99 \mathrm{~kg}$ ) are more likely to return compared to lighter weight players $(<79 \mathrm{~kg}) .{ }^{16}$ Concomitant knee injuries or surgical factors such as graft type have not been associated with return to play rates. ${ }^{16,33}$

Lai et $\mathrm{al}^{33}$ identified two further factors that were significantly associated with an increased incidence of return to play, and these factors were match experience and draft pick order. Specifically, having more than 50 AFL matches of playing experience was associated with a $24 \%$ higher return to play rate and a high draft pick (first round or priority pick) was associated with a $21 \%$ higher return to play rate. Similar findings have been reported in the NFL and may indicate that players who have demonstrated their ability to play at the elite level and are regarded by their team as highly talented may be more likely to be given the opportunity to return to play. ${ }^{37}$ Determinants of return to play have not been investigated for the AFLW or non-elite levels of Australian football.

\section{Playing Performance}

Overall, it is reasonable to conclude that ACL reconstruction has a negative impact on subsequent playing performance in AFL players. Despite the high overall rates of return to play, one of the most significant challenges appears to be the ability to return to play on a consistent basis. ${ }^{38}$ Specifically, only half of those who return to elite level AFL competition after surgery play a minimum of 10 matches over two full seasons, which is less than a quarter of scheduled matches. ${ }^{38}$ This likely has a significant impact on both the player and their team.

Performance pre- versus post-injury and ACL reconstruction has also been measured with the use of various player statistics. Using mean ball disposals across 5 games as a performance metric, Liptak et $\mathrm{al}^{16}$ showed that players did not return to preinjury form by 3 years after return to play compared with preinjury. In a more detailed analysis with the use of ranking points per match (RPPM) formulated by Champion data (official provider of AFL statistics), which encompasses ball possession, movement, scoring and defensive actions, Lai et $\mathrm{al}^{38}$ showed that $68 \%$ of players who had returned to play on a regular basis were at their preinjury level of performance by the second post-surgical season. When compared to the League average, all players who returned to regular match play performed at a level that was comparable to the AFL average level.

Various factors have been examined for their association with a return to preinjury performance in AFL players. Younger aged ( $<25$ years) and lighter weight $(<$ $90 \mathrm{~kg}$ ) players have almost three times the odds of return to their preinjury performance. ${ }^{38}$ However, the reasons for this are unclear and may simply relate to play list management decisions. Football-related factors such as early or late draft pick, amount of playing experience or playing position have not been associated with a return to performance. ${ }^{38}$ Similarly, injury-related factors such as the preferred kicking limb, presence of concomitant knee injuries or type of graft used in the reconstruction surgery have not been shown to be related to player return to preinjury level of performance. ${ }^{38}$

\section{Subsequent ACL Injury}

Rates of further ACL injury in the AFL are high, as the 1990-2000 audit reported that $28 \%$ of players who returned to play after ACL reconstruction sustained a subsequent ACL injury. ${ }^{16}$ The $1999-2013$ audit confirmed that these high rates have continued over time, with $30 \%$ of players sustaining subsequent ACL injury over the 15 -year audit period. ${ }^{33}$ Second ACL injuries to the ipsilateral knee occurred at a higher rate than contralateral ACL injuries, and they also occurred significantly earlier than contralateral ACL injuries; at a mean 15 months after reconstruction surgery, compared to 35 months.

The 1999-2013 audit highlighted that younger age at the time of the first ACL injury was a significant risk factor for subsequent ACL injury. Specifically, 50\% of players aged under 21 sustained a subsequent ACL injury during their AFL career. ${ }^{33}$ Having played fewer AFL matches before the first ACL injury was associated with an almost 2-fold increase in the risk for subsequent ACL injury. A positive family history was also associated with 
an almost four-fold increased risk for contralateral ACL injury, but not with a graft rupture. ${ }^{33}$

The timing of return to competition has also been examined to determine whether an early return is associated with an increased risk of reinjury. ${ }^{34}$ In this analysis, 233 AFL players who returned to play after autograft ACL reconstruction were grouped based on the time they returned to competition, at $<10$ months, $10-12$ months or $>12$ months. Players who returned at 10-12 months had the lowest ACL injury risk per game. Players who returned before 10 months had the next highest risk but also played the greatest number of post-injury career games. Interestingly, players who returned after 12 months had the highest per game ACL injury risk and played the fewest post-injury career games. As such, there may be a "sweet spot" in time where both early and late return to play leads to suboptimal outcomes. ${ }^{34}$

Whilst the use of LARS grafts has, as noted previously in this section, resulted in a faster return to play in the AFL, it has also been associated with a significantly increased risk for revision reconstruction as compared with autografts. Four of the six (67\%) players who received a LARS graft for primary reconstruction underwent subsequent revision surgery during or after their AFL career. ${ }^{33}$ Similar findings were reported with the use of LARS grafts for revision procedures, with a further revision performed in $50 \%$ ( 5 out of 10 ) of players. These patient numbers are small but they represent the largest published series of elite athletes who have undergone ACL reconstruction with LARS grafts. ${ }^{33}$ Potential selection bias must be acknowledged as most LARS procedures were performed on players with a previous ACL injury to either knee. Nonetheless, that $50-67 \%$ of LARS procedures required further revision surgery does indicate that this may be a risky treatment option for this high-demand sport in athletes with multiple risk factors for subsequent ACL injury.

At a non-elite level, there are no published reinjury data specific to Australian football. For this review, and to allow for comparison with elite level athletes, raw data were extracted from a prior study that examined the high reinjury rates in younger patients after ACL reconstruction, and included non-elite Australian football players. ${ }^{39}$ There were 113 males between the ages of 12-19 who had undergone hamstring tendon graft ACL reconstruction. At a mean follow-up of five years, there were 45 (40\%) players who had sustained a subsequent ACL injury. Second injury rates were even higher at $48 \%$ (28 out of
59) for players who were under 18 years at the time of surgery. This limited data documents that even at a nonelite level, young males who participate in Australian football are at significant risk for sustaining multiple ACL injuries. The high subsequent ACL injury rate at all levels of participation in Australian football is highly concerning and future work is needed to determine whether similar reinjury rates occur in female Australian football players.

\section{Conclusion}

Australian football is a high-risk sport for ACL injury as the nature of play reproduces the musculoskeletal kinematics that elicit the ACL injury mechanism on the field. Australian football has traditionally been largely played by males; however, the introduction of an elite level women's competition in 2017 has seen a rapid growth in female participation. Unfortunately, there is a high incidence of ACL injuries in women who play Australian football at the elite level, and at the nonelite and junior levels the incidence rate of ACL injuries is currently unknown. Return to sport outcomes at the elite male level have been well documented. Most elite males who participate in the AFL return to play; however, only half return on a regular basis and at least a third do not return to preinjury levels of performance. Subsequent ACL injury is highly prevalent and occurs in approximately a third of all elite male athletes and 50\% of elite males who are young (under 25 years) at the time of injury. At the non-elite level, a similarly high proportion of male football players suffer multiple ACL injuries. There is a paucity of data on reinjury rates in female Australian football players. This review highlights that while an ACL injury does not mean the end of a player's career, it certainly presents a significant challenge with regard to return to play and subsequent injury.

\section{Abbreviations}

ACL, anterior cruciate ligament; AFL, Australian Football League; AFLW, Australian Football League Women's; LARS, Ligament Augmentation and Reconstruction System; RPPM, ranking points per match.

\section{Disclosure}

The authors report no conflicts of interest in this work. 


\section{References}

1. Australian Football League. Australian Football League Annual Report 2019. Melbourne: Victoria Australia; 2019.

2. Denham G Australian football riding a player boom as AFLW takes off. The Australian; February 25, 2019.

3. Gray AJ, Jenkins DG. Match analysis and the physiological demands of Australian football. Sports Med. 2010;40(4):347-360. doi:10.2165/ 11531400-000000000-00000

4. Clarke AC, Ryan S, Couvalias G, Dascombe BJ, Coutts AJ, Kempton T. Physical demands and technical performance in Australian Football League Women's (AFLW) competition matchplay. J Sci Med Sport. 2018;21(7):748-752. doi:10.1016/j. jsams.2017.11.018

5. Haycraft JAZ, Kovalchik S, Pyne DB, Robertson S. Physical characteristics of players within the Australian football league participation pathways: a systematic review. Sports Med Open. 2017;3(1):46. doi:10.1186/s40798-017-0109-9

6. Haycraft JAZ, Kovalchik S, Pyne DB, Robertson S. Classification of players across the Australian rules football participation pathway based on physical characteristics. J Strength Cond Res. 2020. doi:10.1519/JSC.0000000000003503

7. Waterworth B. AFL 2019: Telstra tracker data reveals league's fastest players and distance kings so far this season; 2019.

8. Saal JA. Common American football injuries. Sports Med. 1991;12 (2):132-147. doi:10.2165/00007256-199112020-00005

9. López-Valenciano A, Raya-González J, Garcia-Gómez JA, et al. Injury profile in women's Football: a systematic Review and meta-analysis. Sports Med. 2021;51(3):423-442. doi:10.1007/s40279-020-01401-w

10. López-Valenciano A, Ruiz-Pérez I, Garcia-Gómez A, et al. Epidemiology of injuries in professional football: a systematic review and meta-analysis. $\mathrm{Br} \quad J$ Sports Med. 2020;54(12):711-718. doi:10.1136/bjsports-2018-099577

11. Montalvo AM, Schneider DK, Yut L, et al. "What's my risk of sustaining an ACL injury while playing sports?" A systematic review with meta-analysis. Br J Sports Med. 2019;53(16):1003-1012. doi:10.1136/bjsports-2016-096274

12. Orchard J, Seward H. Epidemiology of injuries in the Australian Football League, seasons 1997-2000. Br J Sports Med. 2002;36 (1):39-44. doi:10.1136/bjsm.36.1.39

13. Saw R, Finch CF, Samra D, et al. Injuries in Australian rules Football: an overview of injury rates, patterns, and mechanisms across all levels of play. Sports Health. 2018;10(3):208-216. doi: $10.1177 / 1941738117726070$

14. Australian Football League. 2019 AFL injury Report. Melbourne, Victoria Australia: AFL Doctors Association, AFL Physiotherapists Association, AFL Football Operations Department; 2019.

15. Orchard J, Seward H, McGivern J, Hood S. Intrinsic and extrinsic risk factors for anterior cruciate ligament injury in Australian footballers. Am J Sports Med. 2001;29(2):196-200. doi:10.1177/ 03635465010290021301

16. Liptak MG, Angel KR. Return to play and player performance after anterior cruciate ligament injury in elite Australian rules football players. Orthop J Sports Med. 2017;5(6):2325967117711885.

17. Walden M, Hagglund M, Magnusson H, Ekstrand J. Anterior cruciate ligament injury in elite football: a prospective three-cohort study. Knee Surg Sports Traumatol Arthrosc. 2011;19(1):11-19. doi:10.1007/s00167-010-1170-9

18. Myklebust G, Maehlum S, Engebretsen L, Strand T, Solheim E. Registration of cruciate ligament injuries in Norwegian top level team handball. A prospective study covering two seasons. Scand $J$ Med Sci Sports. 1997;7(5):289-292. doi:10.1111/j.16000838.1997.tb00155.x
19. Janssen KW, Orchard JW, Driscoll TR, van Mechelen W. High incidence and costs for anterior cruciate ligament reconstructions performed in Australia from 2003-2004 to 2007-2008: time for an anterior cruciate ligament register by Scandinavian model? Scand $J$ Med Sci Sports. 2012;22(4):495-501. doi:10.1111/j.16000838.2010.01253.x

20. Orchard J, Seward H, McGivern J, Hood S. Rainfall, evaporation and the risk of non-contact anterior cruciate ligament injury in the Australian football league. Med J Aust. 1999;170(7):304-306. doi:10.5694/j.1326-5377.1999.tb127782.x

21. Orchard JW, Walden M, Hagglund M, et al. Comparison of injury incidences between football teams playing in different climatic regions. Open Access J. 2013;4:251-260.

22. Orchard J. Is there a relationship between ground and climatic conditions and injuries in football? Sports Med. 2002;32(7):419-432. doi:10.2165/00007256-200232070-00002

23. Waldén $\mathrm{M}$, Hägglund $\mathrm{M}$, Orchard $\mathrm{J}$, Kristenson $\mathrm{K}$, Ekstrand $\mathrm{J}$. Regional differences in injury incidence in European professional football. Scand J Med Sci Sports. 2013;23(4):424-430. doi:10.1111/ j.1600-0838.2011.01409.x

24. Twomey DM, Finch CF, Lloyd DG, Elliott BC, Doyle TL. Ground hardness and injury in community level Australian football. $J$ Sci Med Sport. 2012;15(4):305-310. doi:10.1016/j.jsams.2011.12.003

25. Donnelly CJ, Elliott BC, Doyle TL, Finch CF, Dempsey AR, Lloyd DG. Changes in knee joint biomechanics following balance and technique training and a season of Australian football. Br J Sports Med. 2012;46 (13):917-922. doi:10.1136/bjsports-2011-090829

26. Cochrane JL, Lloyd DG, Buttfield A, Seward H, McGivern J. Characteristics of anterior cruciate ligament injuries in Australian football. J Sci Med Sport. 2007;10(2):96-104. doi:10.1016/j. jsams.2006.05.015

27. Annear J Anterior cruciate ligament injuries: overview of treatment and management of ACL in AFL football. Sports Link; 2002:6-7.

28. Finch CF, Twomey DM, Fortington LV, et al. Preventing Australian football injuries with a targeted neuromuscular control exercise programme: comparative injury rates from a training intervention delivered in a clustered randomised controlled trial. Inj Prev. 2016;22 (2):123-128. doi:10.1136/injuryprev-2015-041667

29. Snyder L, Kadlec D, Nimphius S. The when, where and how of anterior cruciate ligament injury in Australian football league Women's. J Aust Strength Cond. 2019;27(6):39.

30. Hewett TE, Myer GD. The mechanistic connection between the trunk, hip, knee, and anterior cruciate ligament injury. Exerc Sport Sci Rev. 2011;39(4):161-166. doi:10.1097/JES.0b013e3182297439

31. Bruder AM, Crossley KM, Mosler AB, Patterson B, Haberfield M, Donaldson A. Co-creation of a sport-specific anterior cruciate ligament injury risk reduction program for women: a concept mapping approach. J Sci Med Sport. 2020;23(4):353-360. doi:10.1016/j. jsams.2019.10.019

32. Webster KE, Hewett TE. Meta-analysis of meta-analyses of anterior cruciate ligament injury reduction training programs. J Orthop Res. 2018;36(10):2696-2708. doi:10.1002/jor.24043

33. Lai CCH, Feller JA, Webster KE.J. Fifteen-year audit of anterior cruciate ligament reconstructions in the Australian football league from 1999 to 2013: Return to play and subsequent ACL injury. Am J Sports Med. 2018;46(14):3353-3360. doi:1177/0363546518803932

34. Chaker Jomaa M, Gultekin S, Orchard J, Driscoll T, Orchard J. Australian footballers returning from anterior cruciate ligament reconstruction later than 12 months have worse outcomes. Indian J. 2020;54(3):317-323.

35. Okoroha KR, Kadri O, Keller RA, Marshall N, Cizmic Z, Moutzouros V. Return to play after revision anterior cruciate ligament reconstruction in national football league players. Orthop. 2017;5 (4):2325967117698788. 
36. Ardern CL, Webster KE, Taylor NF, Feller JA. Return to the preinjury level of competitive sport after anterior cruciate ligament reconstruction surgery. Am J Sports Med. 2011;39(3):538-543. doi: $10.1177 / 0363546510384798$

37. Shah VM, Andrews JR, Fleisig GS, McMichael CS, Lemak LJ. Return to play after anterior cruciate ligament reconstruction in National Football League athletes. Am J Sports Med. 2010;38 (11):2233-2239. doi:10.1177/0363546510372798
38. Lai CCH, Feller JA, Webster KE. Playing performance after anterior cruciate ligament reconstruction among Australian football league players from 1999 to 2013. Am J Sports Med. 2019;47 (7):1550-1556. doi:10.1177/0363546519843908

39. Webster KE, Feller JA. Exploring the high reinjury rate in younger patients undergoing anterior cruciate ligament reconstruction. Am J Sports Med. 2016;44(11):2827-2832. doi:10.1177/0363546516651845

\section{Publish your work in this journal}

Open Access Journal of Sports Medicine is an international, peerreviewed, open access journal publishing original research, reports, reviews and commentaries on all areas of sports medicine. The manuscript management system is completely online and includes a very quick and fair peer-review system. Visit http://www.dovepress. com/testimonials.php to read real quotes from published authors. 